made of a soft metal, aluminium, backed by a harder metal; presumably, contact with a hard platen causes intragranular cracking before the diffusion creep can begin. This soft-plate technique is similar to that used in the very different study of Brookes et al. reported in this issue ${ }^{2}$. These authors achieve plastic deformation in a monocrystal of diamond, the hardest and most brittle of solids. Following earlier work with $\mathrm{MgO}$ and $\mathrm{TiC}$, they reason that a conical indenter pressed on a smooth diamond surface under constant load will - so long as it is slightly softer than the diamond - slowly be blunted until the distributed contact stress has fallen sufficiently for deformation to cease. If the hardness of the indenter is chosen correctly, then the stress in the contact zone is too low to crack the diamond but high enough to deform it plastically. For this to be feasible, the temperature must be very high. An indenter of cubic boron nitride (second only to diamond in hardness) at $1,000{ }^{\circ} \mathrm{C}$ neatly does the trick. The diamond deforms by clearly visible multiple dislocation glide. This temperature is $500{ }^{\circ} \mathrm{C}$ lower than the hitherto-accepted transition from brittleness to slight ductility, as determined by three-point bending ${ }^{14}$.

It would be interesting to know how the grain size of polycrystalline diamond affects its plastic deformability; indeed, it is conceivable that a sufficiently fine grain size could permit a measure of diffusion creep, not linked to the motion of dislocations. In view of the extensive recent work on the formation of microcrystalline-diamond surface coatings by vapour deposition (see ref. 15), such an investigation could be of great practical value.

1. Karch, J., Birringer, R. \& Gleiter, H. Nature 330, 556-558 (1987).

2. Brookes, C.A., Howes, V.R. \& Parry, A.R. Nature 332 139-141 (1988)

3. Brook, R.J. in Encyclopedia of Materials Science and Engineering (ed. Bever, M.B.) 98-105 (Pergamon and MIT, 1986)

4. Birchall, J.D. Phil. Trans. R. Soc. A310, 139-153 (1983).

5. Jack, K.H. in High-Technology Ceramics, Past, Presen and Future; Ceramics and Civilization Vol. III (ed. Kingery, W.D.) 259-288 (Am. Ceramic Soc., Westerville, Kingery,

6. Claussen, N. \& Heuer, A.H. in Encyclopedia of Materials Science and Engineering (ed. Bever, M.B.) 5129-5132 (Pergamon and MIT, 1986).

7. Lange, F.F. J. mater. Sci. 17, 225-263 (1982).

8. Garvie, R.C., Hannink, R.H. \& Pascoe, R.T. Nature 258 703-704 (1975)

9. Zhu, X., Birringer, R., Herr, U. \& Gleiter, H. Phys. Rev B35, 9085-9090 (1987).

10. Herr, U., Jing, J., Birnuger, R., Gonser, U. \& Gleiter, H. J. appl. Phys. 50, $472-474$ (1987).

11. Mütschele, T. \& Kirchheim, R. Scripta Metall. 21, 135-140 (1987).

12. Horvath, J., Birringer, R. \& Gleiter, H. Solid St. Commun. 62, 319-322 (1987).

13. Cahn, R.W. \& Hazzledine, P. in Encyclopedia of Materials Science and Engineering (ed. Bever, M.B.) 4686-4790 (Pergamon and MIT, 1986).

14. Evans, T. \& Wild, R.K. Phil. Mag. 12, 479-486 (1965)

15. Messier, R., Spear, K.E., Badzian, A.R. \& Roy, R. J. Metals, N.Y. 39 (9), 8-11 (1987).

Robert W. Cahn is in the Department of Materials Science and Metallurgy, University of Cambridge, Pembroke Street, Cambridge CB2 $3 Q Z, U K$.

\section{Myth, science and art of Greek peonies}

At an exhibition at the Natural History Museum, Cromwell Road, London SW7, UK until 17 April the peony is used to trace the development of scientific documentation and botanical illustration. Peonies grow wild on the mountains and hills of Greece (the example shown here is the species Paeonia parnassica from Mount Parnassos), and were used 2,000 years ago for medical purposes, being associated with the mythical physician Paeon. The exhibition contains twelve lithographs made from paintings by Niki Goulandris. The lithographer, Takis Katsoulis, used 12-16 zinc plates for each illustration, one for each colour variation. The lithographs were made by printing each plate on a stone or metal press and then superimposing by hand.

\section{Developmental biology}

\section{Growth factors in amphibian cell differentiation}

\section{Hugh Woodland and Liz Jones}

THE molecules that control development are being unveiled at an accelerating rate. What is more striking than anything else is that so many fall into a select band of molecular families. These families, identified by their first members, are growth factors and their receptors, oncogenes and DNA-binding proteins with either zinc fingers or homoeo domains. Very recent examples are wingless, a segmentation gene of the fruitfly Drosophila, related to int-1, a mouse oncogene activated by mammary tumour virus ${ }^{1}$; and dorsal, which is involved in formation of the fly's dorso-ventral axis, and has extensive homology with v-rel, an avian oncogene ${ }^{2}$. Growth factors have an even longer pedigree in this regard. For example, epidermal growth factor (EGF) relatives have a role in cellfate switching in the nematode reproductive system (lin-12) ${ }^{3}$ and between epidermis and nervous system in Drosophila $(\text { notch })^{4}$.

Two papers, one by Kimelman and Kirschner ${ }^{5}$ and the other by Weeks and Melton ${ }^{6}$, published in a recent issue of Cell, suggest that growth factors or their relatives have a role in mesoderm formation and the establishment of the dorso-ventral axis in Amphibia.

\section{Dorso-ventral polarity}

When the amphibian egg is laid it has an obvious pigmented animal pole and a yolky vegetal pole (Fig. 1a). The animal cells develop into ectoderm and the vegetal cells into endoderm. These cells also interact in the blastula, the vegetal cells inducing neighbouring animal cells to become mesoderm. The animal and vegetal cells are the first types to appear and presumably their different properties are established by substances ('determinants') localized in the egg. Without polarization phenomena, triggered by the entry of the sperm, the embryo would develop into a tube of radially symmetrical ventral tissues.

The effect of the sperm is to cause a polarized contraction of the surface regions of the $\mathrm{egg}^{7}$. In turn, this somehow makes the vegetal cells on the dorsal side generate a dorsal mesoderm induction signal (B, Fig. $1 b)$ rather than, or together with, the basal ventral signal (A, Fig $1 b)$. The dorsal mesoderm subsequently - estrates many later developmental 